\title{
Immediate Impact of Uni-nephrectomy among Bangladeshi Healthy Live Kidney Donors: BIRDEM General Hospital Experience
}

\author{
Palash Mitra ${ }^{1}$, Muhammad Abdur Rahim² ${ }^{2}$ Tasrina Samnaz Samdani ${ }^{3}$, \\ Wasim Md. Mohosinul Haque ${ }^{4}$, Sarwar Iqbal ${ }^{4}$, Md. Abul Mansur ${ }^{5}$ \\ Received: June 6, 2015 Accepted: April 16, 2016 \\ doi: http://dx.doi.org/10.3329/jemc.v6i2.27760
}

\begin{abstract}
Background: Kidney transplantation is the preferred treatment option for end stage kidney disease. Live kidney donation is an established form of organ donation; but it carries the risk of an unnecessary surgery in a normal individual. These donors remain at an increased risk of multiple medical problems for the rest of their life. Objective: In this study, we evaluated the immediate impact of uninephrectomy among kidney donors during the period of post-transplant hospital stay. Materials and Methods: This cross-sectional study was done at BIRDEM General Hospital from January 2006 to June 2014. All kidney donors who had undergone graft nephrectomy during the study period were the study population. All the donors underwent Tc-99m diethylene triamine pentaacetic acid (Tc-99m DTPA) renogram for measurement of glomerular filtration rate (GFR). GFR was also estimated by different equations in both pre-transplant and post-transplant periods. Pre-uninephrectomy GFR and post-uninephrectomy GFR of donors were compared. Results: Total number of subjects was 81 , male 48 and female 33. Mean age was $36.3 \pm 9.9$ years. Mean postoperative hospital stay was $8.2 \pm 2.0$ days. The mean pre-operative measured glomerular filtration rate $\left(\mathrm{mGFR} R_{D T P A}\right)$ was $99.54 \pm 19.06 \mathrm{~mL} / \mathrm{min} / 1.73 \mathrm{~m}^{2}$ and mean estimated glomerular filtration rate $\left(e G F R_{C K D-E P I}\right)$ was $99.0 \pm 18.55 \mathrm{~mL} / \mathrm{min} / 1.73 \mathrm{~m}^{2}(p=0.855)$. In post-nephrectomy period mean urine output decreased from $2708.1 \pm 842.8$ to $2228.4 \pm 702.4 \mathrm{~mL} /$ day $(p=0.000)$. Mean SBP lowered from $120.3 \pm 12.5$ to $115.6 \pm 9.2 \mathrm{~mm}$ of $\mathrm{Hg}(p=0.000)$ after nephrectomy. There was significant increase in blood urea (from $19.7 \pm 5.7$ to $30.4 \pm 9.5 \mathrm{mg} / \mathrm{dL}, p=0.000$ ) and serum creatinine (from $0.90 \pm 0.16$ to $1.26 \pm 0.24 \mathrm{mg} / \mathrm{dL}, p=0.000$ ) in post-uninephrectomy period. Mean $m G F R_{D T P A}$ of the subjects of non-nephrectomized kidney of the donors was $49.18 \pm$ $9.50 \mathrm{~mL} / \mathrm{min} / 1.73 \mathrm{~m}^{2}$ and mean eGFR $C K D$-EPI of same kidneys was $69.09 \pm 16.79 \mathrm{~mL} / \mathrm{min} / 1.73 \mathrm{~m}^{2}$ $(p=0.000)$ after uni-nephrectomy. Conclusion: Uninephrectomy in healthy adult kidney donors has immediate impacts on urine output, blood pressure, blood urea and serum creatinine levels.
\end{abstract}

Key words: Uni-nephrectomy; Pre-uninephrectomy; Post-uninephrectomy; Estimated GFR; Live kidney donors

J Enam Med Col 2016; 6(2): 71-74

\section{Introduction}

Kidney transplantation remains the optimum treatment option for patients with end stage kidney disease (ESKD). The incremental shortage of kidneys for

transplantation resulting in long waiting time for prospective kidney transplant recipients and the better graft and patient survival after living kidney

1. Assistant Registrar, Department of Nephrology and Dialysis, BIRDEM General Hospital, Dhaka

2. Assistant Professor, Department of Nephrology and Dialysis, BIRDEM General Hospital, Dhaka

3. Assistant Professor, Department of Medicine, Delta Medical College and Hospital, Dhaka

4. Associate Professor, Department of Nephrology and Dialysis, BIRDEM General Hospital, Dhaka

5. Professor, Department of Nephrology and Dialysis, BIRDEM General Hospital, Dhaka

Correspondence Palash Mitra, Email: palash_mtr@yahoo.com 
transplantation have increased the number of living kidney donations throughout the world. ${ }^{1,2}$ Individuals with two healthy kidneys, proven by a variety of invasive and non-invasive techniques, can donate one kidney. Live kidney donation is an established form of organ donation but carries the risk of an unnecessary surgery in a normal individual for the benefit of the recipient. ${ }^{3}$ Not only that, in the long run, the living kidney donors remain at an increased risk of developing hypertension, dyslipidaemia, chronic kidney disease (CKD), stroke, cardiovascular events and diabetes mellitus. ${ }^{3-6}$ So, it is worth assessing the immediate impact of uninephrectomy among kidney donors to keep a record of baseline effect to foresee the long-term adverse events in subsequent follow-up visits.

Currently, there are no such data regarding impact of unilateral nephrectomy in healthy Bangladeshi people after kidney donation. So, this study was designed to observe the immediate impact of uninephrectomy among kidney donors during the post-transplant hospital stay period.

\section{Materials and Methods}

This cross-sectional study was done at the Youth Foundation Transplant Unit of Diabetic Association of Bangladesh located at Bangladesh Institute of Research and Rehabilitation in Diabetes, Endocrine and Metabolic Disorders (BIRDEM) General Hospital, Dhaka, Bangladesh from January 2006 to June 2014. All kidney donors who had undergone graft nephrectomy in this unit during the study period constituted the study population.

During pre-transplant donor assessment, all donors underwent Tc-99m diethylene triamine pentaacetic acid (Tc-99m DTPA) renogram for measurement of glomerular filtration rate (GFR). GFR was also estimated by different equations in both pre-transplant and post-transplant periods.

DTPA renogram study was conducted on E-Cam, Dual Head SPECT Gamma Camera, manufactured by Siemens, Germany. Each study subject required to be on normal diet and well hydrated orally for 30 minutes before initiation of study. $5 \mathrm{mCi}$ Tc99m-DTPA was injected intravenously and dynamic images of kidneys were taken in total of 87 frames. Total study time was 30 minutes. The calculated DTPA-GFR was used as the

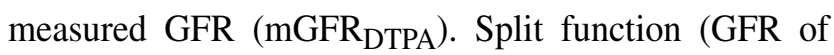
individual kidney) of each kidney was also measured by
DTPA renogram and the mGFR DTPA $_{\text {of the non- }}$ nephrectomized kidney was later compared with eGFR during post-operative period.

Estimated glomerular filtration rate (eGFR) was calculated using the following equations.

- Modification of Diet in Renal Disease (MDRD) formula:

$$
\begin{aligned}
& \mathrm{eGFR}_{\mathrm{MDRD}}\left(\mathrm{mL} / \mathrm{min} / 1.73 \mathrm{~m}^{2}\right) \\
& =175 \times(\mathrm{S} . \mathrm{Cr})^{-1.154} \times(\mathrm{Age})^{-0.203} \times 0.742 \text { (if } \\
& \text { female }) \times 1.212 \text { (if black) }
\end{aligned}
$$

- Chronic Kidney Disease Epidemiology (CKDEPI) equation:

$$
\begin{aligned}
& \operatorname{eGFR}_{\text {CKD-EPI }}\left(\mathrm{mL} / \mathrm{min} / 1.73 \mathrm{~m}^{2}\right) \\
& =141 \times \min (\mathrm{S} . \mathrm{Cr} / \mathrm{k}, 1)^{\mathrm{a}} \times \max (\mathrm{S} . \mathrm{Cr} / \mathrm{k}, 1)^{-1.209} \\
& \times 0.993^{\text {age }} \times 1.018(\text { if female }) \times 1.159 \text { (if black), }
\end{aligned}
$$

where $\mathrm{k}$ is 0.7 for women and 0.9 for men, a is -0.329 for women and -0.411 for men, $\min$ indicates the minimum of $\mathrm{S}$. $\mathrm{Cr} / \mathrm{kr}$ or 1 , and max indicates the maximum of $\mathrm{S} . \mathrm{Cr} / \mathrm{k}$ or 1 .

Data were presented as mean \pm SD or frequency and percentages, depending on the data type. Statistical analyses were performed using SPSS software (version 20.0) and MedCalc 11.2.1.0 (Medcalc, Mariakerke, Belgium). All tests were 2-tailed and the results were considered significant when the $\mathrm{p}$ value was below 0.05 .

\section{Results}

In this study total number of subjects was 81 , male 48 and female 33 . Mean age of the study population was $36.3 \pm 9.9$ years. Their mean post-operative hospital stay period was $8.2 \pm 2.0$ days. One patient $(1.2 \%)$ suffered from wound infection and one (1.2\%) from respiratory tract infection during post-operative hospital stay. Significant changes were observed in 24 hours urine output, systolic blood pressure, blood urea and serum creatinine levels between pre- and postuninephrectomy periods (Table I).

Among these donors, 7 (8.6\%) had blood urea level above the normal value $(40 \mathrm{mg} / \mathrm{dL})$ and $39(48.1 \%)$ had mildly raised serum creatinine level $(>1.2 \mathrm{mg} / \mathrm{dL})$ during discharge from hospital after graft nephrectomy.

The comparison between mGFR ${ }_{\text {DTPA }}$, GFR $_{M D R D}$ and eGFR $_{\text {CKD-EPI }}$ in pre-uninephrectomy period is shown in Table II and post-uninephrectomy period in Table III. The eGFR was a bit lower than mGFR in pre-operative 
assesments, but the eGFR was higher than the mGFR of the non-nephrectomized kidney during the postuninephrectomy comparison.

Table I: Comparison of different parameters of live kidney donors between pre-and post-nephrectomy period

\begin{tabular}{|l|c|c|c|}
\hline Parameters & $\begin{array}{c}\text { Pre-uninephrectomy } \\
\text { period }\end{array}$ & $\begin{array}{c}\text { Post-uninephrectomy } \\
\text { period }\end{array}$ & p values \\
\hline $\begin{array}{l}\text { Mean urine output } \\
\text { (mL/day) }\end{array}$ & $2708.1 \pm 842.8$ & $2228.4 \pm 702.4$ & 0.000 \\
\hline $\begin{array}{l}\text { Mean systolic BP } \\
\text { (mm of Hg) }\end{array}$ & $120.3 \pm 12.5$ & $115.6 \pm 9.2$ & 0.000 \\
\hline $\begin{array}{l}\text { Mean diastolic BP } \\
\text { (mm of Hg) }\end{array}$ & $77.4 \pm 6.9$ & $76.1 \pm 7.1$ & 0.159 \\
\hline $\begin{array}{l}\text { Mean blood urea } \\
\text { (mg/dL) }\end{array}$ & $19.7 \pm 5.7$ & $30.4 \pm 9.5$ & 0.000 \\
\hline $\begin{array}{l}\text { Mean serum creatinine } \\
\text { (mg/dL) }\end{array}$ & $0.90 \pm 0.16$ & $1.26 \pm 0.24$ & 0.000 \\
\hline
\end{tabular}

Table II: Comparison of measured and estimated GFR in preuninephrectomy period

\begin{tabular}{|l|c|c|c|}
\hline Parameters & $\begin{array}{c}\text { Value } \\
\left(\mathrm{mL} / \mathrm{min} / 1.73 \mathrm{~m}^{2}\right)\end{array}$ & Mean difference & $p$ values \\
\hline mGFR & $99.54 \pm 19.06$ & -- & -- \\
\hline eGFR & $94.40 \pm 20.36$ & -5.41 & 0.074 \\
\hline eGFR & & -0.54 & 0.579 \\
\hline
\end{tabular}

Table III: Comparison of measured and estimated GFR in post-uninephrectomy period

\begin{tabular}{|l|c|c|c|}
\hline Parameters & $\begin{array}{c}\text { Value } \\
\left(\mathrm{mL} / \mathrm{min} / 1.73 \mathrm{~m}^{2}\right)\end{array}$ & Mean difference & $\mathrm{p}$ values \\
\hline mGFR & $49.18 \pm 9.50$ & -- & -- \\
\hline eGFRA & $60.47 \pm 13.92$ & +11.29 & $<0.0001$ \\
\hline eGFR & & & \\
\hline
\end{tabular}

\section{Discussion}

The first successful kidney transplantation from one human to another was done in $1954^{7}$ and since then kidney transplantation has become the preferred treatment for patients with ESKD. In Bangladesh, first kidney transplantation was done in $1982^{8}$ and in our center kidney transplantation was started in 2004.

Living related donors supply $100 \%$ of renal allografts in our country. In United States, living donors supply approximately $40 \%$ of renal allografts. ${ }^{6}$ The perioperative mortality of donors after nephrectomy is approximately 3 per 10,000 cases. Major and minor perioperative complications affect approximately 3-6\% and 22\% of donors respectively. Donor nephrectomy neither appears to increase long-term mortality compared with controls nor it appears to increase ESKD risk among white donors. ${ }^{6}$ But, the likelihood of postdonation CKD and medical co-morbidities such as hypertension and diabetes appear to be relatively higher among some donor subgroups, such as African Americans and obese donors. ${ }^{6}$

In our center, we started keeping records of immediate impacts of donor nephrectomy in postoperative hospital stay periods. There was significant decrease in urine output and systolic blood pressure and increase in blood urea and serum creatinine levels during post-operative periods. Though there was no significant difference between measured GFR and estimated GFR pre-operatively, but in immediate post-nephrectomy period, both eGFR $_{\text {CKD-EPI }}$ and eGFR ${ }_{\text {MDRD of non-nephrecto- }}$ mized kidney was found significantly higher compared to preoperative mGFR $_{\mathrm{DTPA}}$ of the same kidney obtained by split function. Almost similar results were reported in three different studies conducted by Chung et al, Tang et al and Lin et al. ${ }^{9-11}$ This difference in GFR may be due to the limitations of the GFR estimating equations. The GFR estimating equations formulated for CKD patients are dependent on ethnicity and body surface area (BSA). Accuracy is not yet proven in our region. These equations were formulated for patients with two kidneys and accuracy in case of persons with normal renal function and solitary kidney is yet to be proven. So, this significant increase in eGFR in post-nephrectomy period among donors may be due to the compensatory mechanism or due to improper equation for estimating GFR in uni-nephrectomized patients, which is yet to be validated. In postnephrectomy period, GFR measurement was avoided as it poses increased risk of contrastinduced nephropathy to the single native kidney.

Current study was a single center study and the sample size was small. We have evaluated the immediate post-operative events and we have the plan to follow up these donors longitudinally, though even in United States, national follow-up of living donors is limited in scope, duration and completeness. ${ }^{6}$ 
In conclusion, it can be said that besides complications related to surgery, uni-nephrectomy has its immediate impact on urine output, blood pressure and renal function. The long term effect of these on renal function has to be evaluated in live kidney donors of Bangladesh. It would be beneficial for the donors if an appropriate equation for estimating GFR can be formulated to estimate GFR among healthy kidney donors, even after uni-nephrectomy. It would help the renal transplant team to monitor the post-transplant renal function status of the donor more accurately without posing any threat to the remaining single kidney.

\section{References}

1. Koo DDH, Welsh KI, McLaren AJ, Roake JA, Morris PJ, Fughle SV. Cadaver versus living donor kidneys: impact of donor factors on antigen induction before transplantation. Kidney International 1999; 56: 1551-1559.

2. Davis CL, Delmonico FL. Living donor kidney transplantation: a review of the current practices for the live donor. $\mathrm{J}$ Am Soc Nephrol 2005; 16: 2098-2110.

3. Sahay M, Anuradha NG. Risk of live kidney donation-Indian perspective. J Assoc Physicians India 2007; 55: 267-270.

4. Chu KH, Poon CK, Lam CM, Cheuk A, Yim KF, Lee W et al. Long-term outcomes of living kidney donors: a single center experience of 29 years. Nephrology (Carlton) 2012; 17(1): 85-88.
5. Tsai SF, Shu KH, Ho HC, Wu MJ, Cheng CH, Lian JD et al. Long-term outcome in living donors over the past 28 years in a single center in Taiwan. Transplant Proc 2012; 44(1): $39-42$.

6. Lentine KL, Patel A. Risks and outcome of living donation. Adv Chronic Kidney Dis 2012; 19(4): 220-228.

7. Erogul M, Sinert RH, Cobb EM, Harriott AJN. Transplants, Renal. eMedicine. James Li, Talavera F, Sinert RH, Halamka JD, Schraga ED (eds). 5 Dec. 2008. Medscape. Available at: http://www.emedicine.medscape.com/article/778255overview. Accessed November 2011.

8. Rahman MH. Prospect of renal transplantation in Bangladesh [Editorial]. Bangladesh J Urol 2011; 14(1): 1.

9. Chung BH, Yu JH, Cho HJ, Kim J, Moon IS, Park CW et al. Comparison of estimating equations for the prediction of glomerular filtration rate in kidney donors before and after kidney donation. PLoS One 2013; 8(4): e60720. doi: 10.1371/journal.pone.0060720.

10. Tan JC, Ho B, Busque S, Blouch K, Derby G, Efron B et al. Imprecision of creatinine-based GFR estimates in uninephric kidney donors. Clin J Am Soc Nephrol 2010; 5: 497-502.

11. Lin J, Knight EL, Hogan LM, Singh AK. A comparison of prediction equations for estimating glomerular filtration rate in adult without kidney disease. J Am Soc Nephrol 2003; 14 : 2573-2580. 